\title{
Impact of DNA damaging agents on genome-wide transcriptional profiles in two marine Synechococcus species
}

\section{Sasha G. Tetu ${ }^{1}$, Daniel A. Johnson ${ }^{2}$, Deepa Varkey ${ }^{1}$, Katherine Phillippy ${ }^{2+}$, Rhona K. Stuart ${ }^{3}$, Chris L. Dupont ${ }^{3,4}$, Karl A. Hassan ${ }^{1}$, Brian Palenik $^{3}$ and lan T. Paulsen ${ }^{1 *}$}

1 Department of Chemistry and Biomolecular Sciences, Macquarie University, Sydney, NSW, Australia

${ }^{2}$ Microbial and Environmental Genomics Department, J. Craig Venter Institute, Rockville, MD, USA

${ }^{3}$ Marine Biology Research Division, Scripps Institution of Oceanography, University of California, San Diego, CA, USA

${ }^{4}$ Microbial and Environmental Genomics Department, J. Craig Venter Institute, San Diego, CA, USA

Edited by:

Martin G. Klotz, University of North

Carolina at Charlotte, USA

\section{Reviewed by:}

Martin Hagemann, University

Rostock, Germany

Donald A. Bryant, The Pennsylvania

State University, USA

\section{*Correspondence:}

lan T. Paulsen, Department of

Chemistry and Biomolecular

Sciences, Eastern Ave, Macquarie

University, Sydney, 2109 NSW,

Australia

e-mail: ian.paulsen@mq.edu.au

${ }^{\dagger}$ Present address:

Katherine Phillippy, National Center for Biotechnology Information, National Library of Medicine, National Institute of Health,

Bethesda, USA
Marine microorganisms, particularly those residing in coastal areas, may come in contact with any number of chemicals of environmental or xenobiotic origin. The sensitivity and response of marine cyanobacteria to such chemicals is, at present, poorly understood. We have looked at the transcriptional response of well characterized Synechococcus open ocean (WH8102) and coastal (CC9311) isolates to two DNA damaging agents, mitomycin $\mathrm{C}$ and ethidium bromide, using whole-genome expression microarrays. The coastal strain showed differential regulation of a larger proportion of its genome following "shock" treatment with each agent. Many of the orthologous genes in these strains, including those encoding sensor kinases, showed different transcriptional responses, with the CC9311 genes more likely to show significant changes in both treatments. While the overall response of each strain was considerably different, there were distinct transcriptional responses common to both strains observed for each DNA damaging agent, linked to the mode of action of each chemical. In both CC9311 and WH8102 there was evidence of SOS response induction under mitomycin $C$ treatment, with genes recA, lexA and umuC significantly upregulated in this experiment but not under ethidium bromide treatment. Conversely, ethidium bromide treatment tended to result in upregulation of the DNA-directed RNA polymerase genes, not observed following mitomycin $\mathrm{C}$ treatment. Interestingly, a large number of genes residing on putative genomic island regions of each genome also showed significant upregulation under one or both chemical treatments.

Keywords: cyanobacteria, Synechococcus, transcriptome, microarray, toxic stress, ethidium bromide, mitomycin C, DNA damage

\section{INTRODUCTION}

Ocean environments comprise a vast component of the Earth's biosphere and play a key role in global biogeochemical processes. Unicellular marine cyanobacteria, including Synechococcus and Prochlorococcus species, are estimated to constitute $20-40 \%$ of total marine chlorophyll biomass and carbon fixation, and hence significantly impact the carbon cycle and global climate processes (Partensky et al., 1999). Considering their ecological importance, it is important to understand what stresses these organisms are susceptible to and how they respond to these challenges.

In recent years work has begun to unravel the gene level responses of Synechococcus and Prochlorococcus to a range of environmental stressors. Nitrogen limitation is thought to be common in the marine environment and these microbes have regulatory systems such as NtcA for regulating their responses to nitrogen (Lindell and Post, 2001). Phosphate limitation stress is also an issue in some marine environments and a subset of cyanobacteria encode the $\mathrm{PhoB} / \mathrm{R}$ two component regulatory systems for responding to this (Tetu et al., 2009). Another challenge is high irradiance, especially UV wavelengths (Llabres and Agusti, 2006), and adaptation to high light conditions in marine Synechococcus involves expression of genes whose products are involved with dissipation of excess light, scavenging to eliminate reactive oxygen species and changes to photosynthetic machinery (Scanlan et al., 2009; Mella-Flores et al., 2012). Marine cyanobacteria have been shown to be more sensitive to copper stress than eukaryotic phytoplankton and their response to this stress has been characterized at the transcriptional level (Stuart et al., 2009). Iron, which is necessary for photosynthetic apparatus, is also considered to be important in the ecology of marine cyanobacteria, and transcriptional responses to changing iron availability have been characterized in Prochlorococcus strains (Thompson et al., 2011).

In contrast, relatively few studies to date have focused on how marine cyanobacteria respond to toxic chemicals, despite the finding of multidrug-like efflux systems in marine cyanobacterial genomes (Palenik et al., 2003). Numerous chemicals, including both xenobiotics and compounds produced by other 
marine microbes potentially impact these important primary producers, particularly in coastal regions. Toxicity tests on marine Synechococcus have indicated that these species are particularly sensitive to exposure to the herbicide atrazine, possibly due to their small cell size and relatively high surface area to volume ratio (Weiner et al., 2004).

Genome sequences are now available for a number of marine cyanobacteria, including Synechococcus sp. WH8102, isolated from tropical Atlantic Ocean waters (Palenik et al., 2003), Synechococcus sp. CC9311 isolated from coastal waters (Palenik et al., 2006) as well as a number of others from habitats including the Sargasso Sea, Red Sea and the Mediterranean (Palenik et al., 2006; Dufresne et al., 2008). The availability of whole genome sequences allows comparative genomic analyses and techniques such as microarray analysis to be employed to elucidate mechanisms by which cyanobacteria cope with different challenges, such as exposure to toxic compounds.

To gain insight into how different strains of Synechococcus respond to toxic chemical exposure, microarray experiments were carried out on an open ocean and a coastal strain using ethidium bromide (EB) and mitomycin C (MC). For each chemical a "shock" treatment ( $2 \mathrm{~h}$ exposure) was applied, as examining short time courses reduces secondary effects due to long term toxicity. These two compounds were chosen as they are both DNA damaging agents which have different modes of action that have been well characterized previously. EB binds to DNA by intercalation between base pairs in the DNA helix, resulting in inhibition of DNA-directed RNA synthesis (Richardson, 1973). MC is a potent DNA cross-linker known to be capable of inducing the SOS response system in many bacterial species (Janion, 2008) and has been used to induce cyanobacterial prophages in environmental samples [for example (Sode et al., 1994)]. The SOS response, which occurs after single stranded DNA accumulates in a cell, is a global response to DNA damage that results in induction of DNA repair and mutagenesis pathways. In well studied bacteria, such as Escherichia coli, it is known to result in activation of RecA, which in turn inactivates the LexA repressor, decreasing the pool of this protein which during normal growth negatively regulates a set of genes including $u m u D$ and $u m u C$ involved in mutagenic repair (Janion, 2008). While some cyanobacteria such as the well studied freshwater species Synechocystis sp. PCC 6803 have lost the classic E. coli type LexA mediated SOS response (Domain et al., 2004), recent analyses of marine cyanobacteria Prochlorococcus marinus PCC9511 and Synechococcus sp. WH7803 have demonstrated a typical, coordinated SOS response to DNA damage, involving lexA and recA (Kolowrat et al., 2010; Blot et al., 2011).

Whilst neither EB nor MC is currently considered as a significant environmental pollutant and to our knowledge there is at present no information regarding levels of either chemical in the environment, both have been synthesized for more than 50 years, inevitably resulting in some degree of environmental exposure. Mitomycin $\mathrm{C}$ has a long history of use as an antitumor drug in the treatment of a wide range of cancers and is marketed in most countries worldwide (Bradner, 2001). In addition to a long history of routine laboratory use as a DNA stain, EB has been widely used in veterinary medicine to treat cattle infected with trypanosomes, a use which continues in parts of the world despite recent concerns regarding its mutagenicity (Roy Chowdhury et al., 2010). EB has also been widely used as a marker for multidrug efflux [for example (Mitchell et al., 1999; Patel et al., 2010; Hassan et al., 2011)] which makes it a particularly good test compound to gain comparative insights into the role of putative efflux pumps encoded within Synechococcus genomes in detoxification of the cell.

We hypothesized that a coastal Synechococcus strain would have a more robust response to chemical toxicant stress since xenobiotic compounds [likely sources include stormwater, industrial and agricultural runoff (Nogales et al., 2011)] and other toxic chemicals [for example antibiotics produced by marine bacteria (Long et al., 2003)] are likely to be in higher concentrations in coastal environments.

\section{METHODS}

\section{Strains and growth conditions}

Axenic Synechococcus sp. WH8102 and Synechococcus sp. CC9311 cultures (referred to as WH8102 and CC9311) were maintained in either SN (Waterbury and Willey, 1988) medium made with seawater from the Scripps Pier (Scripps Institution of Oceanography, La Jolla, CA), or in an artificial seawater medium (SOW) prepared as described previously ( $\mathrm{Su}$ et al., 2006) with $9.0 \mathrm{mM}$ $\mathrm{NaNO}_{3}$ standard. For growth assays, batch cultures were grown in glass flasks, gently stirred, or in glass tubes, at $25^{\circ} \mathrm{C}$ under $30 \mu \mathrm{mol}$ photons $\mathrm{m}^{-2} \mathrm{~s}^{-1}$ continuous white light. Chemical treatments were performed using each compound at a concentration that was inhibitory to long-term growth, $2 \mu \mathrm{g} / \mathrm{mL}$ for $\mathrm{EB}$ and $0.5 \mu \mathrm{g} / \mathrm{mL}$ for MC (Figure A1). To evaluate cell health at the time which chemical treated cells were harvested, flow cytometry (FACSCalibur, Becton Dickinson) was used to examine cell size and pigmentation. To investigate how these strains respond to these chemical treatments in terms of photosynthetic performance, a saturation pulse $(200 \mathrm{~ms})$ was applied to cells using a PHYTO-PAM fluorescence measuring system equipped with an emitter-detector-cuvette assembly unit ED-101US/D (Walz) to determine the quantum yield of photosystem II at multiple time points after the addition of each compound.

\section{RNA isolation}

Synechococcus strains were grown in 1.5-liter batch cultures to the early exponential phase (approximately $1.5 \times 10^{8}$ cells $/ \mathrm{ml}$ ), and half the culture was centrifuged at room temperature at $10,400 \times \mathrm{g}$, and immediately resuspended in Trizol reagent (Invitrogen), then frozen at $-80^{\circ} \mathrm{C}$ for RNA extraction in parallel with treated cells. EB (final concentration $2 \mu \mathrm{g} / \mathrm{mL}$ ) or $\mathrm{MC}$ (final concentration $0.5 \mu \mathrm{g} / \mathrm{mL}$ ) were added to the remaining culture. After a two hour incubation, these cells were harvested and suspended in Trizol reagent as outlined above. Total RNA was extracted from the cell pellet using Trizol reagent (Invitrogen) according to the manufacturer's instructions. The RNA was resuspended in $100 \mu \mathrm{l}$ of DEPC-treated water. Using the RNeasy Mini kit (Qiagen) and following the manufacturer's protocol, the RNA was twice digested with DNase I (Qiagen) then eluted from the columns. The purity and yield of RNA was determined spectrophotometrically by measuring optical density at wavelengths of 260 and $280 \mathrm{~nm}$. Samples were stored at $-80^{\circ} \mathrm{C}$. 


\section{DNA microarray transcriptional profiling}

Full genome microarrays were synthesized for both WH8102 and CC9311 as described previously (Tetu et al., 2009). For WH8102 this consisted of a mixed population of PCR amplicons (2142 genes) and 70-mer oligonucleotides (389 genes), while for CC9311 arrays were constructed with 70-mer oligonucleotides for each of 2,892 genes. Each gene was represented six times on an array. Negative controls were 50\% DMSO-50\% deionized water, and positive controls included Arabidopsis PCR amplicons and 70-mer oligonucleotides. Each microarray experiment included a minimum of two biological replicates and a minimum of three technical replicates for each biological sample, and at least one "dye-swap" experiment per biological replicate.

An indirect labeling method was used to label cDNA as previously described (Peterson et al., 2004), where cDNA is synthesized in the presence of a nucleoside triphosphate analog containing a reactive aminoallyl group to which a fluorescent dye molecule, either cyanine 3 or cyanine 5 ( $\mathrm{Cy} 3 / \mathrm{Cy} 5)$ is coupled. Approximately $4 \mu \mathrm{g}$ of total RNA was used for indirect labeling, leading to the production of approximately $4 \mu \mathrm{g}$ of cDNA with approximately $200 \mathrm{pmol}$ of dye molecule incorporated per microgram of cDNA synthesized. Prior to hybridization, labeled cDNA was scanned spectrophotometrically to ensure optimal dye incorporation per sample for adequate signal intensity.

All hybridizations were performed as previously described (Peterson et al., 2004). Processing of the TIFF images from hybridized arrays was performed using TIGR-Spotfinder (www. tigr.org/software), and the datasets normalized by applying the LOWESS algorithm, using block mode and a smooth parameter of 0.33, available in the TIGR-MIDAS package (www.tigr.org/ software). Statistical analysis was performed on the mean of $\log _{2}$ transformed signal ratios of the replicate spots using the Statistical Analysis of Microarrays (SAM) algorithms (Tusher et al., 2001) with a false discovery rate of less than $1 \%$. Subsequent analyses considered genes significantly up- or downregulated based on a cutoff of $0.4-\log _{2}$-fold/ $-0.4-\log _{2}$-fold change. Descriptions of the microarray experiments, quantitation data, and array design have been deposited into the gene expression omnibus (GEO) database (http://www.ncbi.nlm.nih.gov/geo/) and have been assigned accession number GSE39818. Genome map circular figures were generated to show the location of the upand downregulated genes in each Synechococcus genome using CGview software (Stothard and Wishart, 2005).

To identify sets of genes which displayed similar patterns of expression when exposed to different test conditions, $k$-means clustering analysis (Soukas et al., 2000) was performed using the TIGR Multi-Experiment Viewer TMEV software (Saeed et al., 2003). Gene trees were subsequently generated by average linkage hierarchical clustering with Euclidean distance as the distance metric.

\section{Cloning and expressing sync2766+7}

CC9311 gene sync_2766 (putative RND multidrug efflux transporter) was PCR amplified independently and together with adjacent sync_2767 (putative MFP subunit) using forward primers sync_2766F (5'-CAC CAT GGA ATG CCA GTC AAA ATT CTC$\left.3^{\prime}\right)$ and sync_2767F (5'-CAC CAT GAT TTT GCG GCT TCA
ATC G - $\left.3^{\prime}\right)$ respectively with reverse primer sync_2766R (5'-GTT TTC AGA AGT ATC TGG CAA AGA GTG-3'). PCR products were generated from CC9311 genomic DNA using Phusion polymerase with $\mathrm{HF}$ buffer using the following cycling parameters: 30 cycles $\left(98^{\circ} \mathrm{C}, 10 \mathrm{~s} ; 58^{\circ} \mathrm{C}, 30 \mathrm{~s} ; 72^{\circ} \mathrm{C}, 2 \mathrm{~min} 20 \mathrm{~s}\right)$ after an initial denaturation at $98^{\circ} \mathrm{C}$ for $30 \mathrm{~s}$. Products were cloned into Invitrogen Gateway pENTR/SD/D-TOPO vector and shuttled into pET-DEST42 following manufacturers' instructions [and as described previously (Ding et al., 2005)]. Plasmids containing cloned genes were sequenced prior to analysis to confirm the absence of deleterious mutations.

Immunoblots were conducted on whole cell lysates of E. coli BL21 cells harboring the pET-DEST42 vector with sync_2766 alone and together with sync_2767 or a control pET-DEST42 vector containing Pseudomonas aeruginosa PA01 gene PA0220, a putative amino acid transporter (referred to as the negative control). Cells were grown to mid-exponential phase and gene expression induced with $0.1 \mathrm{mM}$ isopropyl- $\beta-\mathrm{d}$ thiogalactopyranoside (IPTG) for $1 \mathrm{~h}$ at $37^{\circ} \mathrm{C}$. Samples were run on a $10 \%$ SDS-PAGE gel and transferred to a PVDF membrane. Heterologously expressed V5-tagged proteins were detected using anti-V5 monoclonal antibody conjugated with horseradish peroxidase (HRP) (1/5000 dilution). The membranes were developed with chromogenic substrate 4-Chloro-1-Naphthol (4CN).

Broth-dilution MIC analyses were used to evaluate the resistance potential of the putative RND transporter in E. coli BL21(DE3). These analyses were conducted in cells cultured in Mueller-Hinton broth, using standard methodology as described elsewhere (Wiegand et al., 2008). The concentration ranges tested for $\mathrm{MC}$ and $\mathrm{EB}$ were $0-5$ and $0-200 \mu \mathrm{g} / \mathrm{mL}$ respectively.

\section{RESULTS AND DISCUSSION GLOBAL TRANSCRIPTIONAL RESPONSE TO ETHIDIUM BROMIDE AND MITOMYCIN C EXPOSURE}

A total of four sets of global expression microarray experiments were conducted examining the response of coastal strain CC9311 and open-ocean strain WH8102 to exposure to DNA damaging agents EB and MC. In both strains the mRNA levels of a large number of genes was strongly altered by each shock treatment, compared to the control (Table 1). Synechococcus CC9311 showed a particularly high degree of gene transcription up- and downregulation in response to the tested compounds, with more than 200 genes strongly ( $>2$ fold) up- and downregulated by each treatment. (Lists of all significantly up- and downregulated genes for each strain and stress treatment are presented in Table S1). At the time point that gene expression was examined $(2 \mathrm{~h}$ post addition) chemical treatments had not impacted average cell size or pigmentation as assessed by flow cytometry (data not shown). Measurements of photosynthetic quantum yield for each strain after chemical addition indicated that major reduction in photosynthetic activity occurred after the $2 \mathrm{~h}$ time point at which RNA was harvested (Figure A2).

\section{TRANSCRIPTIONAL RESPONSES VARIED FOR GENES IN DIFFERENT FUNCTIONAL CATEGORIES}

To explore each organism's response to the applied toxic chemical stresses, genes showing significant changes in transcription 
levels were grouped according to clusters of orthologous groups (COG) functional categories (Table 2). As expected, genes in the "DNA replication, recombination and repair" grouping tended to be transcriptionally upregulated in both strains under both stress conditions. In CC9311 genes in the "posttranslational modification, protein turnover, chaperone" category also tended to be transcriptionally upregulated, whilst in WH8102 these genes were disproportionately downregulated, particularly under conditions of EB stress. For example, both strains have genes encoding molecular chaperone DnaK2 heat shock protein homologs (SYNW2508 and sync_2923). In CC9311 this gene was significantly upregulated under both stress conditions, while the homolog in WH8102 was significantly downregulated in the EB treatment (no significant change in MC treatment). Genes encoding proteases FtsH2 and FtsH3 (sync_0355 and sync_0825/
SYNW0305 and SYNW1587) DnaJ protein (sync_0023 and SYNW0024) and co-chaperone GrpE (sync_0022 and SYNW0023) similarly showed transcriptional upregulation in CC9311 and downregulation or no significant change in WH8102.

Interestingly, in CC9311 transcription of "secondary metabolite biosynthesis, transport and catabolism" related genes was affected differently by the two toxins, showing a tendency toward upregulation in EB and downregulation in MC treatment (Table 2). A high proportion of genes in the "energy production and metabolism" grouping were transcriptionally downregulated in both strains, although the trend was especially pronounced in WH8102. The "nucleotide transport and metabolism" category genes were also observed to be disproportionately downregulated in both treatments in both strains (Table 2).

Table 1 | Numbers of genes in Synechococcus sp. WH8102 and CC9311 whose transcription was strongly (more than twofold) upregulated or downregulated under EB and MC shock treatments as detected by microarray analysis.

\begin{tabular}{lllll}
\hline Strain & \multicolumn{2}{c}{ EB } & & \multicolumn{1}{c}{ MC } \\
\cline { 2 - 4 } & Upregulated & Downregulated & Upregulated & Downregulated \\
\hline WH8102 & $97(317)$ & $77(382)$ & $93(236)$ & $80(301)$ \\
CC9311 & $255(786)$ & $228(781)$ & $211(715)$ & $226(745)$ \\
\hline
\end{tabular}

Total numbers of significantly affected genes are given in brackets.

Table 2 | Proportion of Synechococcus sp. CC9311 and WH8102 genes assigned to each COG category that were significantly transcriptionally upregulated and downregulated by EB or MC treatment.

\begin{tabular}{|c|c|c|c|c|c|c|c|c|c|}
\hline & \multirow{3}{*}{ COG function } & \multicolumn{4}{|c|}{ CC9311 } & \multicolumn{4}{|c|}{ WH8102 } \\
\hline & & \multicolumn{2}{|c|}{ EB } & \multicolumn{2}{|c|}{ MC } & \multicolumn{2}{|c|}{ EB } & \multicolumn{2}{|c|}{ MC } \\
\hline & & $\% \uparrow$ & $\% \downarrow$ & $\% \uparrow$ & $\% \downarrow$ & $\% \uparrow$ & $\% \downarrow$ & $\% \uparrow$ & $\% \downarrow$ \\
\hline $\mathrm{Q}$ & Secondary metabolites biosynthesis, transport and catabolism & 36 & 21 & 14 & 36 & 17 & 0 & 13 & 17 \\
\hline$P$ & Inorganic ion transport and metabolism & 23 & 25 & 32 & 26 & 16 & 27 & 10 & 18 \\
\hline I & Lipid metabolism & 34 & 34 & 18 & 28 & 7 & 13 & 9 & 13 \\
\hline $\mathrm{H}$ & Coenzyme metabolism & 23 & 28 & 20 & 28 & 3 & 16 & 5 & 7 \\
\hline $\mathrm{F}$ & Nucleotide transport and metabolism & 18 & 42 & 18 & 25 & 0 & 15 & 0 & 15 \\
\hline$E$ & Amino acid transport and metabolism & 21 & 32 & 23 & 25 & 9 & 25 & 3 & 14 \\
\hline $\mathrm{G}$ & Carbohydrate transport and metabolism & 13 & 30 & 19 & 31 & 7 & 20 & 9 & 14 \\
\hline $\mathrm{O}$ & Posttranslational modification, protein turnover, chaperones & 37 & 18 & 32 & 17 & 10 & 32 & 10 & 9 \\
\hline C & Energy production and conversion & 18 & 32 & 20 & 34 & 10 & 34 & 6 & 20 \\
\hline$U$ & Intracellular trafficking and secretion & 25 & 19 & 13 & 6 & 12 & 24 & 12 & 0 \\
\hline $\mathrm{N}$ & Cell motility and secretion & 8 & 15 & 31 & 31 & 13 & 0 & 0 & 13 \\
\hline M & Cell wall/membrane/envelope biogenesis & 27 & 20 & 27 & 18 & 10 & 14 & 9 & 7 \\
\hline $\mathrm{T}$ & Signal transduction mechanisms & 25 & 40 & 22 & 36 & 17 & 14 & 10 & 17 \\
\hline $\mathrm{D}$ & Cell division and chromosome partitioning & 16 & 47 & 16 & 47 & 14 & 5 & 0 & 0 \\
\hline$L$ & DNA replication, recombination and repair & 36 & 20 & 34 & 13 & 15 & 7 & 15 & 1 \\
\hline $\mathrm{K}$ & Transcription & 33 & 25 & 21 & 25 & 15 & 13 & 6 & 13 \\
\hline$J$ & Translation, ribosomal structure and biogenesis & 24 & 21 & 16 & 37 & 9 & 17 & 5 & 19 \\
\hline V & Defense mechanisms & 41 & 34 & 31 & 25 & 10 & 10 & 13 & 3 \\
\hline $\mathrm{R}$ & General function prediction only & 27 & 21 & 31 & 15 & 10 & 10 & 8 & 6 \\
\hline \multirow[t]{2}{*}{ S } & Function unknown & 26 & 32 & 26 & 23 & 9 & 12 & 4 & 8 \\
\hline & Not in COG & 28 & 27 & 25 & 27 & 18 & 11 & 13 & 14 \\
\hline
\end{tabular}




\section{DNA DAMAGE AGENTS ACTIVATED THE ACCESSORY GENOMES OF BOTH CC9311 AND WH8102}

In both strains many genes within regions previously flagged as putative genomic islands (Palenik et al., 2003, 2006) showed significant transcriptional upregulation in either one or both stress treatments (Figure 1). Fourteen genome regions in WH8102 have been identified with anomalous $\mathrm{G}+\mathrm{C}$ content, ten of which were adjacent to putative phage integrases, potentially representing phage associated genomic islands (Palenik et al., 2003). While these regions contain less than $10 \%$ of the ORFs in this genome, these putative islands contained a surprisingly large proportion of the highly upregulated genes. In the case of EB 37\% of genes upregulated by more than 2 fold (36 of 97 genes) were located in such regions, while for MC stress the proportion was greater still with $47 \%$ of such genes located in putative genomic islands ( 44 of 93 genes upregulated by more than 2 fold). In WH8102 three of the non-phage associated island regions are of particular interest. The region which spans SYNW0424 to SYNW0460 contains a large number of genes which are highly upregulated under MC stress (Figure 1B). Many of the affected genes are predicted to function in carbohydrate modification of the cell envelope (COG:M), including numerous genes annotated as putative glycosyltransferases. The gene region SYNW0951 to SYNW0961 also contains a majority of genes strongly upregulated by MC stress [one exception being SYNW0953 encoding a giant 1.2MDa motility-related protein (Strom et al., 2012)] and to a lesser extent EB stress (most show significant upregulation, but falling below the 2 fold cutoff), however, there is almost no functional information for this set of genes. A third island region spanning SYNW2477 to SYNW2491 contains a cluster of genes strongly upregulated by EB (Figure 1B). This cluster spans the two previously mentioned putative ABC transporter operons predicted to be involved in transport of zinc and cyanate.

In CC9311 previous genome analyses flagged 19 regions of atypical trinucleotide composition as potential genomic islands (Palenik et al., 2006). Again these regions contained a higher than average proportion of the highly upregulated genes in both stress treatments. While these genomic islands contain roughly $4 \%$ of the encoded putative ORFs, more than $10 \%$ of genes upregulated by $>2$ fold in each of the stress treatments were within these genomic regions (28 of 255 in the EB treatment and 26 of 211 in $\mathrm{MC}$ treatment). Again, certain island regions were observed to contain clusters of highly upregulated genes. Most notably the large genomic island region spanning sync_0167 to sync_0193, includes a large number of genes showing high levels of upregulation in one or both stress treatments (Figure 1A). Similar to the large island in WH8102, this island contains a large proportion of genes associated with modification of the cell envelope (COG:M), including genes involved with capsular polysaccharide biosynthesis. Another putative recently horizontally acquired region showing a concentration of highly upregulated genes is the phage associated gene cluster sync_2414 to sync_2448, which encodes mainly genes of unknown function (Figure 1A). Putative RND multidrug efflux transporter encoding genes sync_2766 and sync_2767, which were upregulated by more than 2 fold in both stress treatment, are also located in a putative genomic island region.

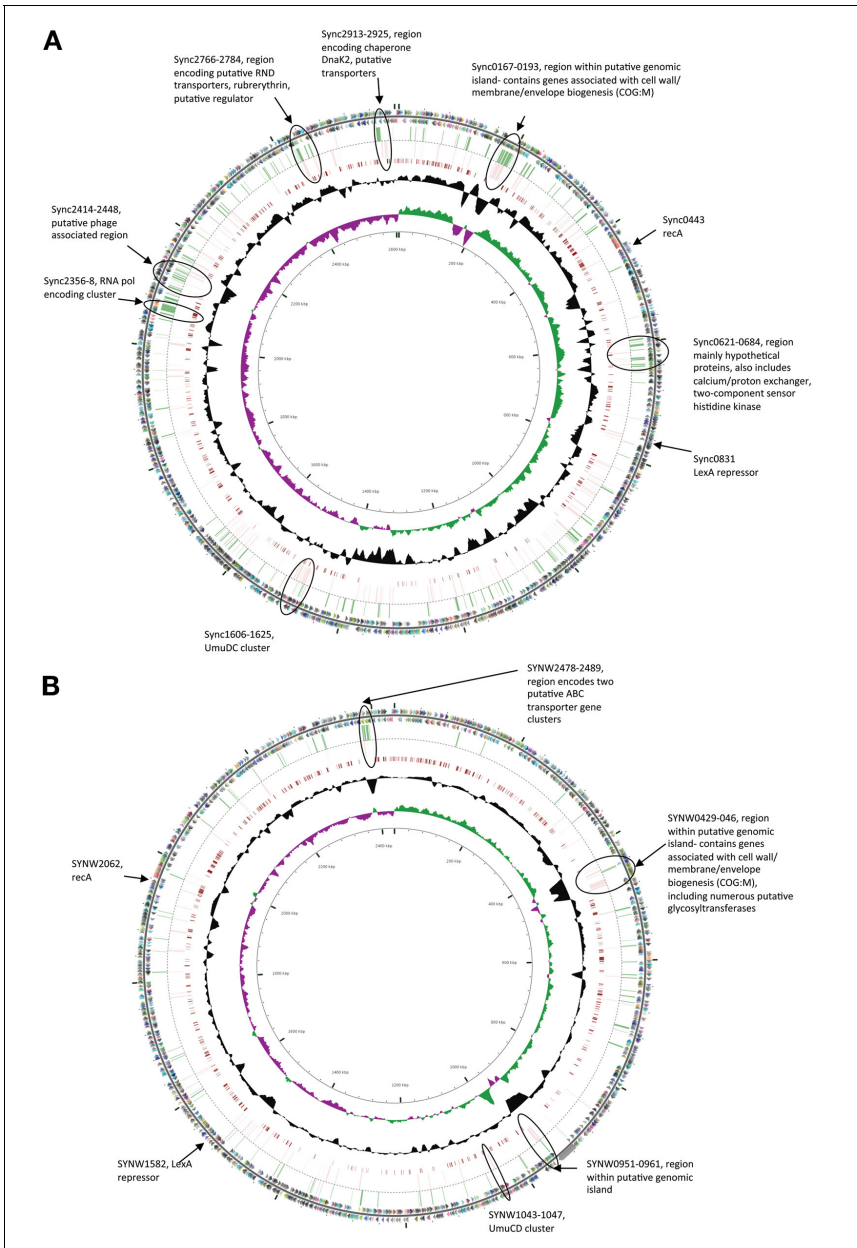

FIGURE 1 | Circular figures showing chromosomes of Synechococcus sp. CC9311 (A) and WH8102 (B) indicating location of genes strongly upregulated ( $>2$ fold) by EB and MC treatments. Outermost two circles indicate positions of CDSs in plus (circle 1) and minus (circle 2) strands colored by functional category: translation, ribosomal structure, and biogenesis (pink); transcription (orange); DNA replication, recombination and repair (fuchsia); cell division and chromosome partitioning (yellow); posttranslational modification, protein turnover, chaperones (brown); cell wall/membrane/envelope biogenesis (olive); cell motility and secretion (dark green); inorganic ion transport and metabolism (green); signal transduction mechanisms (blue/green); energy production and conversion (aqua); carbohydrate transport and metabolism (blue); amino acid transport and metabolism (teal); nucleotide transport and metabolism (turquoise); coenzyme metabolism (dark blue); lipid metabolism (lavender);

secondary-metabolite biosynthesis, transport, and catabolism (purple); general function prediction only (light gray); function unknown (dark gray); and no COG (gray black). Genes whose expression was upregulated by more than 2 fold in microarray experiments when exposed to EB are indicated by green bars in the third circle, while those similarly upregulated by $\mathrm{MC}$ are indicted by pink bars in the fourth circle. Moving toward the center, the next circle map pairwise blastn alignments (expected threshold $=1 \mathrm{e}-20$ ) between CC9311 and WH8102. Circle six shows $\mathrm{G}+\mathrm{C}$ content (deviation from average), and the seventh circle illustrates $G+C$ skew in green (+) and purple (-). The scale (in Kbp) is indicated on the innermost circle. Genes of particular interest are circled and described.

Interestingly, other stress treatments in cyanobacterial strains have also resulted in a disproportionally high impact on transcription of genes within genomic island regions. In Prochlorococcus MED4 and MIT9313 a large fraction of the 
differentially expressed genes in response to iron starvation were observed to reside on genomic islands and/or hypervariable regions (Thompson et al., 2011). Copper shock experiments in Synechococcus CC9311 also resulted in upregulation of a large number of genes in genomic island regions (Stuart et al., 2009), and recent examination of particular genes in these island regions has shown genomic island genes can confer adaptive advantage to stress conditions (Stuart et al., 2013).

\section{COMPARISON OF DNA DAMAGE STRESS RESPONSES FOR CC9311 AND WH8102}

Many of the orthologous genes shared by these two Synechococcus genomes showed different transcriptional responses in the two test strains following each shock treatment. In CC9311 many of the genes observed to be strongly downregulated ( $>2$ fold) in EB stress have orthologs in WH8102 (155/288), however, only 10 of these orthologs were strongly downregulated in WH8102 (Table A1). Similarly for the 112 strongly upregulated CC9311 genes which have orthologs, only eight of these also showed greater than 2 fold upregulation in WH8102. The results of the MC shock treatment were similarly divergent between the two strains (Table A1). While a smaller number of WH8102 genes with orthologs in CC9311 showed high ( $>2$ fold) up and downregulation, again only a small proportion of the CC9311 orthologs responded in the same way (Table A1). In all experiments a small number of orthologous genes responded in the opposite fashion in the two tested strains, for example showing strong upregulation in one strain and strong downregulation in the other, or vice versa (Table A1). In previous work looking at the response of these two Synechococcus strains to copper shock there was also only a modest overlap in significantly regulated orthologous genes (Stuart et al., 2009).

Previous genome analyses of both strains have shown a distinct difference in the two-component regulatory systems of these strains; WH8102 encodes relatively few histidine kinase sensors, only five compared to CC9311, which has 11 (Palenik et al., 2006). Analysis of the transcriptional response of these sensor kinase genes revealed significant upregulation of six of these genes in CC9311 in at least one of the toxicant exposure conditions, while none of the WH8102 genes were significantly upregulated in either condition (Table 3). Sensor kinase sync_0675 in CC9311 showed particularly high levels of upregulation on exposure to both $\mathrm{MC}$ and $\mathrm{EB}$, to our knowledge there has been no previous work into the conditions regulating this gene. These observations suggest that the coastal strain CC9311 has different regulatory circuits to WH8102, which may allow it to react to conditions by switching on or off transcription of a greater proportion of "core" Synechococcus genes, potentially contributing to the higher tolerance/resilience of CC9311 to the tested toxic compounds.

\section{TRANSCRIPTIONAL RESPONSES ARE LINKED TO THE “MODE OF ACTION" OF CHEMICAL TOXICANTS}

In both strains a set of genes showing a significant transcriptional response to both DNA damaging agents was observed. In CC9311 there were 88 genes strongly (more than 2 fold) upregulated and 107 strongly downregulated by both tested compounds. While many of these genes are presently annotated as hypothetical proteins, of those with functional assignations, there were a number encoding regulatory and transport related proteins. These include the two-component response regulator (sync_0115), transcriptional regulator MarR family (sync_2782), two type II alternative RNA polymerase sigma factors (sync_0098, sync_1018) and the sensor histidine kinase (sync_0675) previously discussed. In addition, the genes encoding the protease FtsH2 (sync_0355) and components of a putative RND multidrug efflux transporter (sync_2766 and sync_2767) were transcriptionally upregulated. The strong transcriptional increase observed for the regulatory protein-encoding genes in CC9311 may account for the large proportion of this genome which is affected by these stresses, as these regulators may affect transcription of numerous other genes. WH8102 encodes a homolog only for sync_0115, gene SYNW0126, which itself was not significantly upregulated. In WH8102 there were 22 genes strongly upregulated and 23 strongly downregulated by both tested compounds, almost all of which have not been ascribed a function. Those few with functional predictions include an encoded ribosomal protein

Table 3 | Transcriptional response of sensor kinases to toxic shock treatments in Synechococcus sp. CC9311 and WH8102.

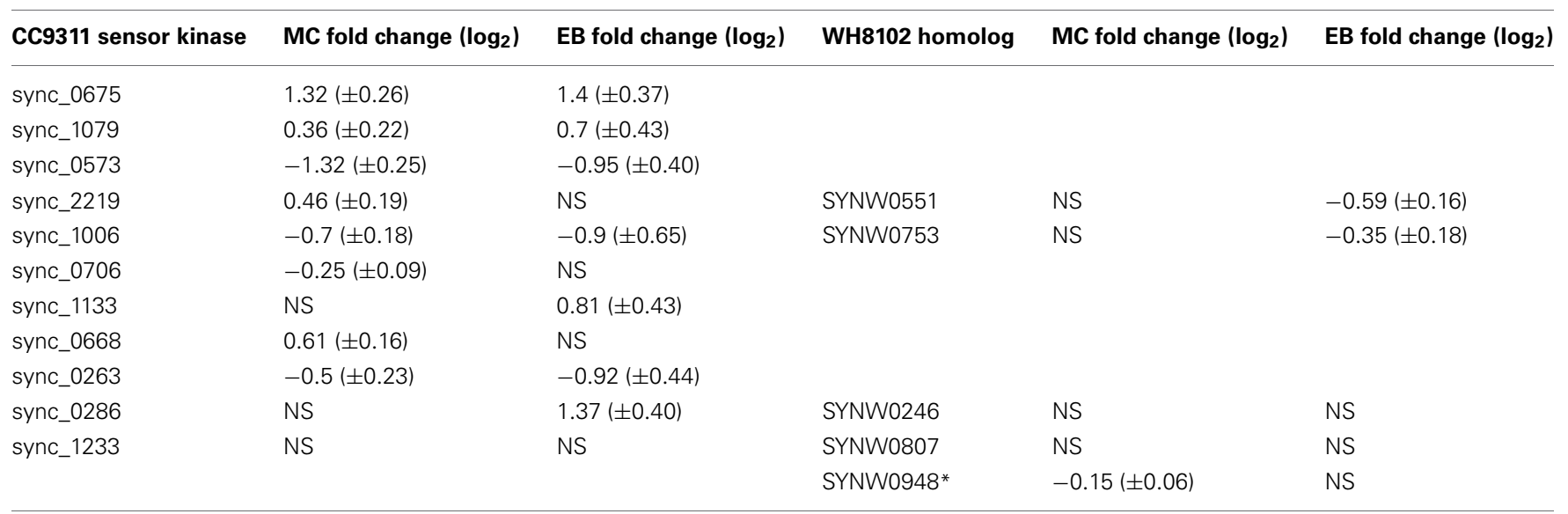

${ }^{*}$ SYNW0948 is involved in phosphate sensing and has no CC9311 homolog. 
SYNW2091, ABC transporter component SYNW2479 and CpeT homolog SYNW2003.

While there were overlaps in the transcriptional response between the two shock treatments, there were also clear differences in the response to each chemical, many of which can be accounted for by differences in the mode of action of these compounds. MC is a potent DNA crosslinker and is known to be capable of inducing the SOS response system in many bacterial species (Janion, 2008), while EB binds to DNA by intercalation between base pairs in the DNA helix, resulting in inhibition of DNA-directed RNA synthesis (Richardson, 1973). In both strains there was evidence of SOS response induction under MC treatment. In both CC9311 and WH8102 genes encoding RecA (sync0443/ SYNW2062), the LexA repressor (sync0831/ SYNW1582) and UmuC (sync1607/SYNW1043) were significantly upregulated under MC but not under EB treatment. Another gene, sync1474/SYNW1405, encoding a conserved hypothetical protein present in both examined strains was also highly upregulated under MC treatment but not in the EB experiment. This gene, whose function is presently unknown, appears to be specific to cyanobacteria and has homologs in most sequenced Synechococcus genomes. In CC9311 umuD encoding sync1606 was also significantly upregulated by MC stress (and to a lesser degree in the EB treatment), while the homolog in WH8102 (SYNW1044) was not. Interestingly, in CC9311 there is a cluster of genes downstream of $u m u D C$ that were also significantly upregulated in the MC treatment (sync1608-sync1613, sync1615, sync1620-sync1623) (Figure 1A). However, as most of these encode proteins of unknown function, it is again difficult to speculate on the exact role of this cluster, which may encode a clade specific SOS response.

It has previously been suggested that cyanobacteria lack an SOS response similar to that of E. coli (Domain et al., 2004; Patterson-Fortin et al., 2006) based largely on work in the model freshwater species Synechocystis sp. PCC6803, where LexA appears to instead be involved in carbon assimilation. In this strain the lexA gene is not DNA damage inducible and its amino acid sequence shows loss of residues required for activity of archetypal LexA proteins, which function to repress expression of DNA repair genes in other prokaryotes (Patterson-Fortin et al., 2006). However, recent experimental and bioinformatic analyses have indicated that it is likely that many of the small, marine cyanobacterial species do indeed have an inducible pathway involved in DNA repair, similar to the E. coli SOS response and involving LexA. Li and colleagues examined the available 33 sequenced cyanobacterial genomes and found that, while a small number, including Synechocystis sp. PCC6803, did not harbor a recognizable lexA gene, the majority do encode a LexA homolog with conserved DNA-binding domains (Li et al., 2010). In their analysis of UV stress response in Prochlorococcus marinus PCC9511, Kolowrat and colleagues found that classic, E. coli-like DNA repair pathways appeared to operate, noting conservation of active residues in LexA and the presence of a putative LexA binding site upstream of $r e c A, u m u C, u m u D$ and $l e x A$, and hypothesizing this strain possesses an active SOS response mechanism involving the lexA gene (Kolowrat et al., 2010). Similarly, Synechococcus sp. WH7803 was recently shown to respond to oxidative stress via up-regulation of a putative LexA regulon, which includes lexA, recA and umuDC (Blot et al., 2011).

In their work Li and colleagues computationally predict lexA regulons for CC9311 and WH8102 based on the location of putative LexA boxes within the operator region of a set of genes (Li et al., 2010). Interestingly, only a subset of these genes were found to be significantly upregulated under MC stress in this work, 15 out of 27 for CC 9311 and 10 out of 46 for WH8102 (Table 4) indicating that further refinement of the LexA boxes using experimental information may be possible.

$\mathrm{EB}$, which acts as an inhibitor of DNA-directed RNA synthesis, led to significant transcriptional upregulation of genes encoding DNA-directed RNA polymerases in both organisms. In CC9311 EB treatment resulted in strong upregulation of the DNA-directed RNA polymerase gene cluster sync_2356-2358 and a number of surrounding genes (Figure 1A), none of which were significantly upregulated by MC. In WH8102 two out of three genes in the homologous DNA-directed RNA polymerase gene cluster were significantly upregulated in the EB experiment (SYNW0613 and 0614 but not 0615 ), but to a lower degree, showing $\log _{2}$ fold changes 0.76 and 1.0, respectively. Part of this effect in both species is that EB may be generally inhibiting transcription and the cell is responding by additional DNA-directed RNA polymerase production. In WH8102 EB treatment also resulted in upregulation of two adjacent sets of genes encoding putative ABC transporter encoding operons SYNW2479-2481 and SYNW2485-2487, annotated as putative zinc and cyanate transporters respectively. All but one of these genes (SYNW2479) were not significantly upregulated in the MC treatment. Only two of these genes have homologs in CC9311 (sync_1497/SYNW2479 and sync1498/SYNW2480) and in CC9311 these genes were not significantly affected by EB.

\section{DOES SYIC2766 ENCODE A RND MULTIDRUG EFFLUX TRANSPORTER?}

Among the set of CC9311 genes highly upregulated in both DNA damage treatments were sync_2766 and sync_2767 which are annotated as putative RND multidrug efflux transporter and membrane fusion protein (MFP) subunit respectively. Gene sync_2766 contains a conserved domain AcrB (COG0841), indicative of a cation/multidrug efflux pump, while sync_2767 contains the conserved domain RND_mfp (TIGR01730). These genes reside in a region of the genome which was previously flagged as a putative genomic island and protein BLAST searches with the translated amino acid sequences reveal sporadic distribution in marine cyanobacteria (data not shown). We performed a series of expression studies using sync_2766 cloned independently and together with sync_2767 into expression vector pET-DEST42 in E. coli BL21(DE3) cells to look for evidence of efflux pump activity. Expression was observed by immunoblotting only when both sync_2766 and sync_2767 were present in the construct. Minimum inhibitory concentration (MIC) assays were carried out with both $\mathrm{EB}$ and MC, however, growth of cells expressing sync_2766-7 was not significantly different to the negative control. For EB MICs of $15 \mu \mathrm{g} / \mathrm{mL}$ were routinely observed for both control and experimental constructs, while MICs of $0.09 \mu \mathrm{g} / \mathrm{mL}$ were recorded for MC. In gram-negative 
Table 4 | Transcriptional response of Synechococcus sp. WH8102 and CC9311 genes previously flagged as having predicted LexA boxes (Li et al., 2010).

\begin{tabular}{|c|c|c|c|c|c|}
\hline $\begin{array}{l}\text { WH8102 predicted } \\
\text { LuxA box genes }\end{array}$ & $\begin{array}{l}\text { MC fold change } \\
\left(\log _{2}\right)\end{array}$ & $\begin{array}{l}\text { EB fold change } \\
\left(\log _{2}\right)\end{array}$ & $\begin{array}{l}\text { CC9311 predicted } \\
\text { LuxA box genes }\end{array}$ & $\begin{array}{l}\text { MC fold change } \\
\left(\log _{2}\right)\end{array}$ & $\begin{array}{l}\text { EB fold change } \\
\left(\log _{2}\right)\end{array}$ \\
\hline SYNW0037 & NS & NS & sync_0035 & 0.40 & NS \\
\hline SYNW0450 & NS & NS & sync_0129 & NS & NS \\
\hline SYNW0684 & 1.16 & 0.76 & sync_0443 & 1.48 & 0.58 \\
\hline SYNW0711 & -0.23 & NS & sync_0453 & NS & NS \\
\hline SYNW0714 & NS & NS & sync_0750 & 0.39 & NS \\
\hline SYNW0715 & NS & NS & sync_0751 & 0.33 & NS \\
\hline SYNW0716 & NS & NS & sync_0841 & 0.88 & NS \\
\hline SYNW0717 & NS & NS & sync_0967 & 0.67 & NS \\
\hline SYNW0718 & NS & NS & sync_1344 & 0.96 & 0.66 \\
\hline SYNW0874 & -0.37 & NS & sync_1558 & -1.79 & -2.26 \\
\hline SYNW0958 & 0.82 & NS & sync_1596 & NS & 0.93 \\
\hline SYNW0959 & NS & NS & sync_1606 & 4.10 & 1.15 \\
\hline SYNW1043 & 1.39 & 0.26 & sync_1607 & 2.25 & 0.79 \\
\hline SYNW1044 & NS & NS & sync_1623 & 3.68 & 1.02 \\
\hline SYNW1045 & 1.01 & NS & sync_2244 & -0.60 & NS \\
\hline SYNW1138 & 1.98 & 0.32 & sync_2245 & -0.52 & NS \\
\hline SYNW1140 & 0.33 & 0.21 & sync_2246 & NS & -0.88 \\
\hline SYNW1148 & NS & NS & sync_2247 & -0.77 & -0.69 \\
\hline SYNW1149 & NS & NS & sync_2248 & -0.60 & -1.24 \\
\hline SYNW1203 & NS & NS & sync_2443 & NS & NS \\
\hline SYNW2106 & NS & NS & & & \\
\hline SYNW2107 & NS & NS & & & \\
\hline SYNW2108 & NS & -0.61 & & & \\
\hline SYNW2109 & NS & -0.56 & & & \\
\hline SYNW2110 & NS & NS & & & \\
\hline SYNW2111 & NS & NS & & & \\
\hline SYNW2342 & -0.49 & 0.20 & & & \\
\hline SYNW2343 & NS & NS & & & \\
\hline SYNW2344 & NS & -0.39 & & & \\
\hline SYNW2345 & NS & -0.75 & & & \\
\hline SYNW2346 & NS & -0.37 & & & \\
\hline SYNW2347 & NS & -0.83 & & & \\
\hline SYNW2410 & 0.82 & 1.58 & & & \\
\hline
\end{tabular}

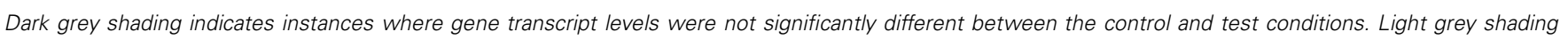
indicates gene transcript levels observed to be significantly reduced in the test condition compared to the control values.

cells, high-level drug resistance mediated by RND efflux systems, typically relies on the formation of tripartite complexes that include an inner-membrane pump (such as sync_2766), a MFP (such as sync_2767) and an outer-membrane spanning channel, which may be distally encoded in the genome (Nikaido and Takatsuka, 2009). High-level resistance may not have been observed from Sync_2766/7 in E. coli, since this organism lacks a cognate outer-membrane protein for this transport system. 
Alternatively, it is possible that the high intrinsic resistance of $E$. coli to these compounds (relative to Synechococcus sp.), may have swamped any efflux activity attributable to sync_2766.

\section{Synechococcus Spp. DISPLAY UNIQUE RESPONSES TO DIFFERENT STRESS CONDITIONS}

Comparing the results of this study to previous microarray experiments on the response of marine Synechococcus to nutrient limitation [phosphate starvation (Tetu et al., 2009), (Ostrowski et al., 2010)] heavy metal stress [copper toxicity (Stuart et al., 2009)] and nickel starvation (Dupont et al., 2012), it appears that the transcriptional response to different "types" of stress tend to be quite specific and can differ substantially between strains. In each study the set of genes showing the highest transcriptional increase differed. In many cases this is not surprising as the function of these genes was clearly linked to the nature of the induced stress, for example increasing transcription of alkaline phosphatases under phosphate starvation conditions and transcriptional activation of SOS response genes after MC treatment.

In the analysis of global transcriptional responses of Synechococcus strains CC9311 and WH8102 to copper toxicity (Stuart et al., 2009) it was shown that the coastal strain CC9311 responded with a more strain specific oxidative or copper acclimation response than the open-ocean strain WH8102, where a more generic stress response was observed. It was also noted that many of the copper toxicity responsive genes in CC9311 may have been acquired by horizontal gene transfer, however, these genes reside in different island regions to those observed to be responsive to $\mathrm{EB}$ and $\mathrm{MC}$. Interestingly, many of the $\mathrm{Cu}$-stress induced WH8102 genes flagged as generic stress response genes, including chaperone proteins DnaJ/DnaK, GroEL/GroES, HtpG and endopeptidase Clp, were observed in this work to be strongly downregulated under conditions of EB toxicity.

One common response observed for both strains following stress with high-copper concentrations and both DNA damaging agents applied in this work was the tendency for photosystem genes to be downregulated. Stuart et al. (2009) reported that of the 37 total photosystem genes, 14 were downregulated in CC9311 while 10 genes were downregulated in WH8102 under high-copper shock conditions, and none of these photosystem genes were upregulated in either strain under these conditions. In this study CC9311 was observed to downregulate 26 photosystem genes under conditions of EB toxicity and 28 when exposed to MC. The open ocean strain WH8102 downregulated 12 photosystem genes when exposed to EB and 24 when exposed to MC. In both cases, however, there were a small number of significantly upregulated photosystem genes (in CC9311 five genes following EB exposure and two genes following MC exposure, in WH8102 three genes following EB exposure). Measurements of photosystem II quantum yield, generated by pulse amplitude modulated fluorometry using the saturation pulse method, indicated that these transcriptional changes occurred before physiologically detectable changes in photosynthesis (Figure A2). Genes involved with nitrate transport also showed a tendency to downregulation in both DNA damage stress and copper shock treatments, with putative nitrate transporters SYNW2463-4 and sync_2899 strongly downregulated in both studies.
The large number of datasets concerning transcriptional responses of WH8102 to a range of stress conditions [copper toxicity (Stuart et al., 2009), phosphate starvation (Tetu et al., 2009) and nickel starvation (Dupont et al., 2012)] enabled us to conduct cluster analyses which revealed a cluster of stress related genes upregulated in most treatments (Figure 2). This set of upregulated genes encodes functions such as Clp endopeptidase, heat shock proteins, chaperones and cell division proteins. However, as noted above, these were typically downregulated in the $\mathrm{EB}$ treatment. This may be due to the possibility that EB directly inhibits transcription (interestingly, late phosphate stress similarly led to downregulation of these genes).

\section{CONCLUSIONS}

Synechococcus sp. WH8102 and CC9311 are useful model marine cyanobacteria and can be used to look at how related organisms which live in different environments (open and coastal ocean, respectively) respond to changes such as exposure to toxicants, nutrient deprivation or other stresses. Genome sequences are available for both of these strains, which have provided insight into the genetic basis for adaptations to their different marine environments. Coastal aquatic environments tend to be more dynamic than open ocean environments and, fitting with this, coastal strain CC9311 was previously observed to have genetic mechanisms which may impart a greater capacity to sense and respond to changes in its environment than open ocean strain WH8102 (Palenik et al., 2006). In this work the two tested strains showed a number of differences in their transcriptional response to each of the DNA damage agents tested. Coastal strain

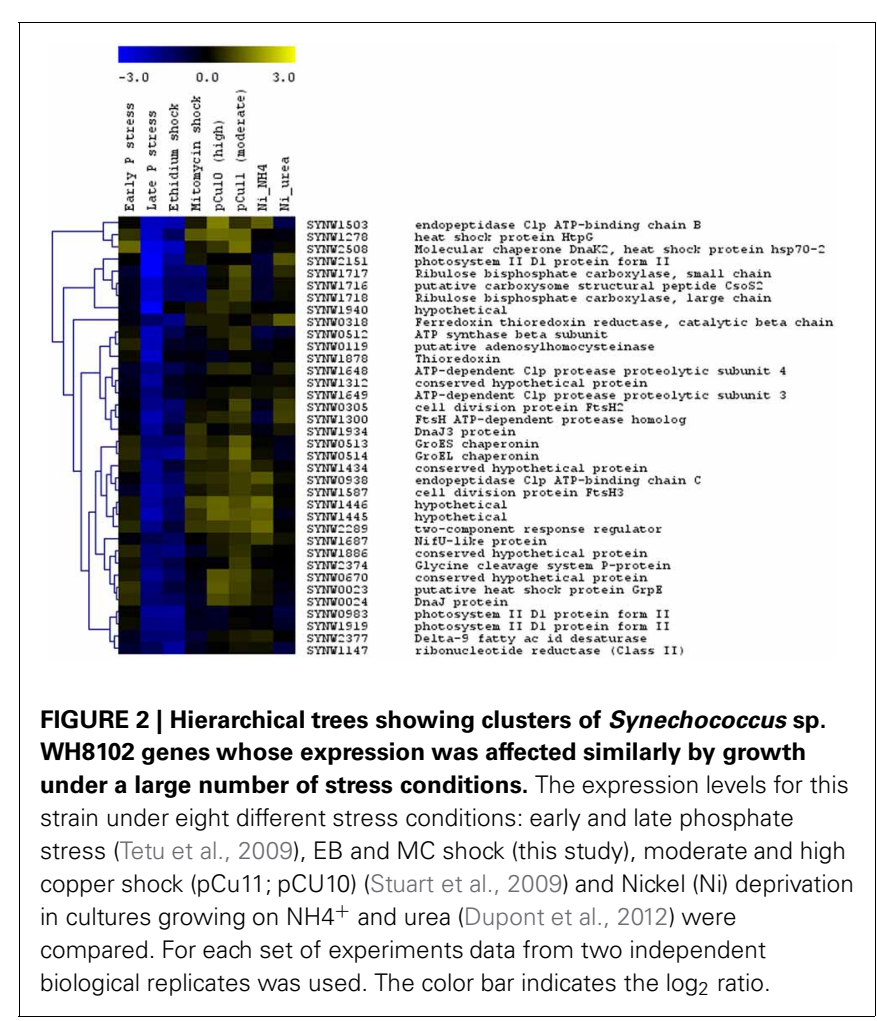


CC9311 was observed to alter transcription of a much greater proportion of the genome in response to both toxic compounds tested. Examination of the orthologous genes shared between the strains showed that genes in CC9311 were more likely to illicit a transcriptional response than their WH8102 counterparts. The coastal strain may be able to elicit a more effective global transcriptional response to these compounds through upregulation of two-component response regulators, which could act to coordinate the transcriptional changes observed in this genome.

The data presented here extends our understanding of how model Synechococcus strains respond to different stress conditions at the global transcriptional level and helps validate SOS regulatory elements in these strains. Our results indicate that strains residing in different niches, e.g., coastal compared to open ocean environments, may elicit quite different global responses to different encountered stresses. Given the importance of these primary producers to global carbon cycling and marine ecosystem health it is important to continue to extend our understanding of Synechococcus stress responses, especially regarding potential anthropogenic pressures.

\section{REFERENCES}

Blot, N., Mella-Flores, D., Six, C., Le Corguille, G., Boutte, C., Peyrat, A., et al. (2011). Light history influences the response of the marine cyanobacterium Synechococcus sp. WH7803 to oxidative stress. Plant Physiol. 156, 1934-1954. doi: 10.1104/pp.111.174714

Bradner, W. T. (2001). Mitomycin C: a clinical update. Cancer Treat. Rev. 27, 35-50. doi: 10.1053/ctrv.2000.0202

Ding, X. Z., Bhattacharjee, A., Nikolich, M. P., Paulsen, I. T., Myers, G., Seshadri, R., et al. (2005). Cloning, expression, and purification of Brucella suis outer membrane proteins. Protein Expr. Purif. 40, 134-141. doi: 10.1016/j.pep.2004.12.017

Domain, F., Houot, L., Chauvat, F., and Cassier-Chauvat, C. (2004). Function and regulation of the cyanobacterial genes lexA, recA and ruvB: LexA is critical to the survival of cells facing inorganic carbon starvation. Mol. Microbiol. 53, 65-80. doi: 10.1111/j.1365-2958.2004.04100.x

Dufresne, A., Ostrowski, M., Scanlan, D. J., Garczarek, L., Mazard, S., Palenik, B. P., et al. (2008). Unraveling the genomic mosaic of a ubiquitous genus of marine cyanobacteria. Genome Biol. 9:R90. doi: 10.1186/gb-2008-9-5-r90

Dupont, C. L., Johnson, D. A., Phillippy, K., Paulsen, I. T., Brahamsha, B., and Palenik, B.
(2012). Genetic identification of a high-affinity Ni transporter and the transcriptional response to $\mathrm{Ni}$ deprivation in Synechococcus sp. strain WH8102. Appl. Environ. Microbiol. 78, 7822-7832. doi: 10.1128/AEM.01739-12

Hassan, K. A., Brzoska, A. J., Wilson, N. L., Eijkelkamp, B. A., Brown, M. H., and Paulsen, I. T. (2011). Roles of DHA2 family transporters in drug resistance and iron homeostasis in Acinetobacter spp. J. Mol. Microbiol. Biotechnol. 000325367

Janion, C. (2008). Inducible SOS response system of DNA repair and mutagenesis in Escherichia coli. Int. J. Biol. Sci. 4, 338-344. doi: 10.7150/ijbs.4.338

Kolowrat, C., Partensky, F., MellaFlores, D., Le Corguille, G., Boutte, C., Blot, N., et al. (2010). Ultraviolet stress delays chromosome replication in light/dark synchronized cells of the marine cyanobacterium Prochlorococcus marinus PCC9511. BMC Microbiol. 10:204. doi: 10.1186/1471-2180-10-204

Li, S., Xu, M. L., and Su, Z. C. (2010). Computational analysis of LexA regulons in Cyanobacteria. BMC Genomics 11:527. doi: 10.1186/1471-2164-11-527

Lindell, D., and Post, A. F. (2001). Ecological aspects of ntcA gene expression and its use as an indicator of the nitrogen status of marine Synechococcus spp. Appl. Environ. 20, 116-124. doi: 10.1159/

\section{ACKNOWLEDGMENTS}

This work was supported by grants from the US Department of Energy's Genomes to Life program (www.doegenomestolife.org) under project Carbon Sequestration in Synechococcus sp.: from Molecular Machines to Hierarchical Modeling, US Department of Energy grant DOE DE-FG03-O1ER63148 to Brian Palenik and Ian T. Paulsen; Australian Research Council Discovery Grant DP110102718: Lifestyle choices: genomic analysis of niche adaptations in marine Synechococcus to Ian T. Paulsen; NSF: MCB0744334 to Brian Palenik. We thank Drs Sophie Mazard and Martin Ostrowski for their assistance with operation of the flow cytometer and PAM fluorometer.

\section{SUPPLEMENTARY MATERIAL}

The Supplementary Material for this article can be found online at http://www.frontiersin.org/Evolutionary_and_Genomic Microbiology/10.3389/fmicb.2013.00232/abstract

\footnotetext{
Table S1 | Complete list of Synechococcus sp. WH8102 and CC9311 genes whose expression was significantly affected by test conditions, according to SAM analysis. Genes are ordered according to $\log _{2}$ fold change (shown in numerator column) with those showing the greatest change in expression under test conditions listed first.
}

Microbiol. 67, 3340-3349. doi: 10.1128/AEM.67.8.3340-3349.2001

Llabres, M., and Agusti, S. (2006). Picophytoplankton cell death induced by UV radiation: evidence for oceanic Atlantic communities. Limnol. Oceanogr. 51, 21-29. doi: 10.4319/lo.2006.51.1.0021

Long, R. A., Qureshi, A., Faulkner, D. J., and Azam, F. (2003). 2n-Pentyl-4-quinolinol produced by a marine Alteromonas sp. and its potential ecological and biogeochemical roles. Appl. Environ. Microbiol. 69, 568-576. doi: 10.1128/AEM.69.1.568-576.2003

Mella-Flores, D., Six, C., Ratin, M., Partensky, F., Boutte, C., Le Corguille, G., et al. (2012). Prochlorococcus and Synechococcus have evolved different adaptive mechanisms to cope with light and UV stress. Front. Microbiol. 3:285. doi: 10.3389/fmicb.2012.00285

Mitchell, B. A., Paulsen, I. T., Brown, M. H., and Skurray, R. A. (1999). Bioenergetics of the staphylococcal multidrug export protein QacA. Identification of distinct binding sites for monovalent and divalent cations. J. Biol. Chem. 274, 3541-3548. doi: 10.1074/jbc.274.6.3541

Nikaido, H., and Takatsuka, Y. (2009). Mechanisms of RND multidrug efflux pumps. Biochim. Biophys. Acta 1794, 769-781. doi: 10.1016/j.bbapap.2008.10.004

Nogales, B., Lanfranconi, M. P., Pina-Villalonga, J. M., and
Bosch, R. (2011). Anthropogenic perturbations in marine microbial communities. FEMS Microbiol. Rev. 35, 275-298. doi 10.1111/j.1574-6976.2010.00248.x

Ostrowski, M., Mazard, S., Tetu, S. G., Phillippy, K., Johnson, A., Palenik, B., et al. (2010). PtrA is required for coordinate regulation of gene expression during phosphate stress in a marine Synechococcus. ISME J. 4, 908-921. doi: 10.1038/ismej.2010.24

Palenik, B., Brahamsha, B., Larimer, F. W., Land, M., Hauser, L., Chain, P., et al. (2003). The genome of a motile marine Synechococcus. Nature 424, 1037-1042. doi: 10.1038/nature01943

Palenik, B., Ren, Q., Dupont, C. L., Myers, G. S., Heidelberg, J. F., Badger, J. H., et al. (2006). Genome sequence of Synechococcus CC9311: insights into adaptation to a coastal environment. Proc. Natl. Acad. Sci. U.S.A. 103, 13555-13559. doi: 10.1073/pnas.0602963103

Partensky, F., Hess, W. R., and Vaulot, D. (1999). Prochlorococcus, a marine photosynthetic prokaryote of global significance. Microbiol. Mol. Biol. Rev. 63, 106-127.

Patel, D., Kosmidis, C., Seo, S. M., and Kaatz, G. W. (2010). Ethidium bromide MIC screening for enhanced efflux pump gene expression or efflux activity in Staphylococcus aureus. Antimicrob. Agents Chemother. 54, 5070-5073. doi: 10.1128/AAC.01058-10 
Patterson-Fortin, L. M., Colvin, K. R., and Owttrim, G. W. (2006). A LexA-related protein regulates redox-sensitive expression of the cyanobacterial RNA helicase, crhR. Nucleic Acids Res. 34, 3446-3454. doi: $10.1093 /$ nar/gkl426

Peterson, S. N., Sung, C. K., Cline, R., Desai, B. V., Snesrud, E. C., Luo, P., et al. (2004). Identification of competence pheromone responsive genes in Streptococcus pneumoniae by use of DNA microarrays. Mol. Microbiol. 51, 1051-1070. doi: 10.1046/j.1365-2958.2003.03907.x

Richardson, J. P. (1973). Mechanism of ethidium bromide inhibition of RNA polymerase. J. Mol. Biol. 78, 703-714. doi: 10.1016/00222836(73)90290-8

Roy Chowdhury, A., Bakshi, R., Wang, J., Yildirir, G., Liu, B., Pappas-Brown, V., et al. (2010). The killing of African trypanosomes by ethidium bromide. PLoS Pathog. 6:e1001226. doi: 10.1371/journal.ppat.1001226

Saeed, A. I., Sharov, V., White, J., Li, J., Liang, W., Bhagabati, N., et al. (2003). TM4: a free, open-source system for microarray data management and analysis. Biotechniques 34, 374-378.

Scanlan, D. J., Ostrowski, M., Mazard, S., Dufresne, A., Garczarek, L., Hess, W. R., et al. (2009). Ecological genomics of marine picocyanobacteria. Microbiol. Mol. Biol. Rev. 73, 249-299. doi: 10.1128/MMBR.00035-08

Sode, K., Oozeki, M., Asakawa, K., Burgess, J., and Matusunaga, T.
(1994). Isolation of a marine cyanophage infecting the unicellular cyanobacterium Synechococcus species NKBG 042902. J. Mar. Biotechnol. 1, 189-192.

Soukas, A., Cohen, P., Socci, N. D. and Friedman, J. M. (2000). Leptinspecific patterns of gene expression in white adipose tissue. Genes Dev. 14, 963-980.

Stothard, P., and Wishart, D. S. (2005). Circular genome visualization and exploration using CGView. Bioinformatics 21, 537-539. doi: 10.1093/bioinformatics/bti054

Strom, S. L., Brahamsha, B. Fredrickson, K. A., Apple, J. K., and Rodriguez, A. G. (2012). A giant cell surface protein in Synechococcus WH8102 inhibits feeding by a dinoflagellate predator. Environ. Microbiol. 14, 807-816. doi: 10.1111/j.1462-2920.2011.02640.x

Stuart, R. K., Brahamsha, B., Busby, K., and Palenik, B. (2013). Genomic island genes in a coastal marine Synechococcus strain confer enhanced tolerance to copper and oxidative stress. ISME J. 75, 5047-5057.

Stuart, R. K., Dupont, C. L., Johnson, D. A., Paulsen, I. T., and Palenik, B. (2009). Coastal strains of marine Synechococcus species exhibit increased tolerance to copper shock and a distinctive transcriptional response relative to those of open-ocean strains. Appl. Environ. Microbiol. 75, 5047-5057. doi: 10.1128/AEM.00271-09

Su, Z., Mao, F., Dam, P., Wu, H. Olman, V., Paulsen, I. T., et al.
(2006). Computational inference and experimental validation of the nitrogen assimilation regulatory network in cyanobacterium Synechococcus sp. WH (8102). Nucleic Acids Res. 34, 1050-1065. doi: 10.1093/nar/gkj496

Tetu, S. G., Brahamsha, B., Johnson, D. A., Tai, V., Phillippy, K., Palenik, B., et al. (2009). Microarray analysis of phosphate regulation in the marine cyanobacterium Synechococcus sp. WH8102. ISME J. 3, 835-849. doi 10.1038/ismej.2009.31

Thompson, A. W., Huang, K. Saito, M. A., and Chisholm S. W. (2011). Transcriptome response of high- and lowlight-adapted Prochlorococcus strains to changing iron availability. ISME J. 5, 1580-1594. doi: 10.1038/ismej.2011.49

Tusher, V. G., Tibshirani, R., and Chu, G. (2001). Significance analysis of microarrays applied to the ionizing radiation response. Proc. Natl. Acad. Sci. U.S.A. 98, 5116-5121. doi: 10.1073/pnas.091062498

Waterbury, J. B., and Willey, J. M. (1988). Isolation and growth of marine planktonic cyanobacteria. Meth. Enzymol. 167, 100-105. doi: 10.1016/0076-6879(88)67009-1

Weiner, J. A., Delorenzo, M. E., and Fulton, M. H. (2004). Relationship between uptake capacity and differential toxicity of the herbicide atrazine in selected microalgal species. Aquat. Toxicol. 68, 121-128. doi: 10.1016/j.aquatox.2004.03.004

Wiegand, I., Hilpert, K., and Hancock, R. E. (2008). Agar and broth dilution methods to determine the minimal inhibitory concentration (MIC) of antimicrobial substances. Nat. Protoc. 3, 163-175. doi: 10.1038/nprot. 2007.521

Conflict of Interest Statement: The authors declare that the research was conducted in the absence of any commercial or financial relationships that could be construed as a potential conflict of interest.

Received: 26 April 2013; accepted: 29 July 2013; published online: 16 August 2013.

Citation: Tetu SG, Johnson DA, Varkey D, Phillippy K, Stuart RK, Dupont CL, Hassan KA, Palenik $B$ and Paulsen IT (2013) Impact of DNA damaging agents on genome-wide transcriptional profiles in two marine Synechococcus species. Front. Microbiol. 4:232. doi: 10.3389/ fmicb.2013.00232

This article was submitted to Evolutionary and Genomic Microbiology, a section of the journal Frontiers in Microbiology.

Copyright (c) 2013 Tetu, Johnson, Varkey, Phillippy, Stuart, Dupont, Hassan, Palenik and Paulsen. This is an open-access article distributed under the terms of the Creative Commons Attribution License (CCBY) The use, distribution or reproduction in other forums is permitted, provided the original author(s) or licensor are credited and that the original publication in this journal is cited, in accordance with accepted academic practice. No use, distribution or reproduction is permitted which does not comply with these terms. 


\section{APPENDIX}

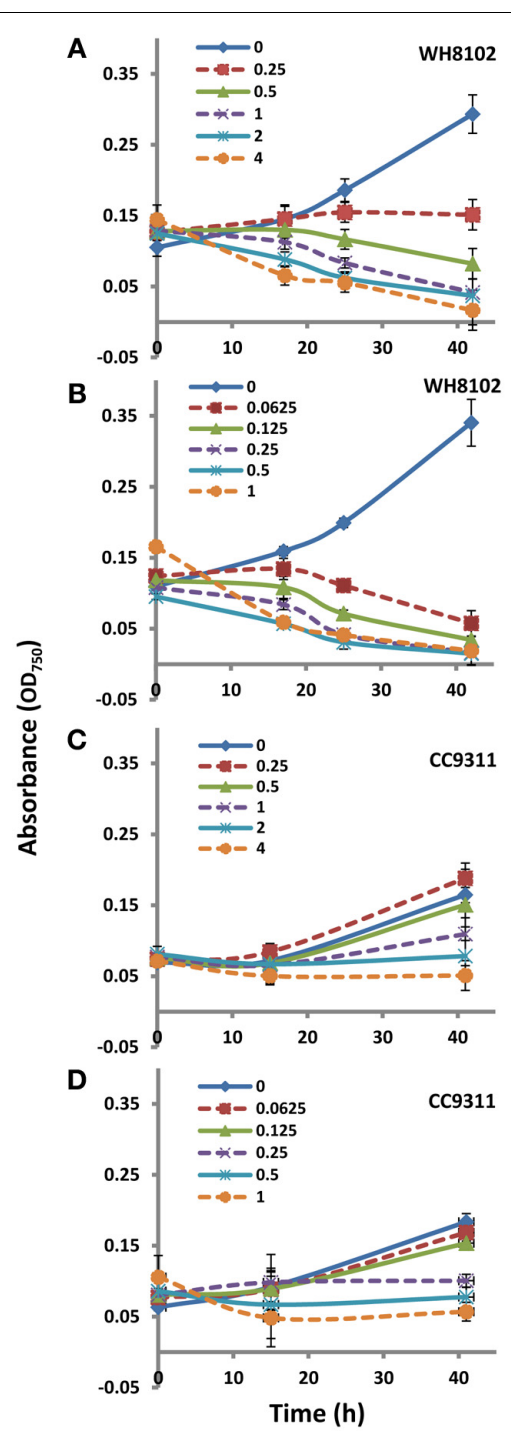

FIGURE A1 | Growth of WH8102 and CC9311 on treatment with EB and $M C$ at concentrations ranging from $0-4$ and $0-1 \mu \mathrm{g} / \mathrm{ml}^{-1}$ respectively. (A) Growth of WH8102 on treatment with EB; (B) Growth of WH8102 on treatment with MC; (C) Growth of CC9311 on treatment with EB; (D) Growth of CC9311 on treatment with MC. The axes represent absorbance at $750 \mathrm{~nm}$ against time in hours. The experiment was conducted in triplicate and the mean plotted. The error bars represent standard deviation.
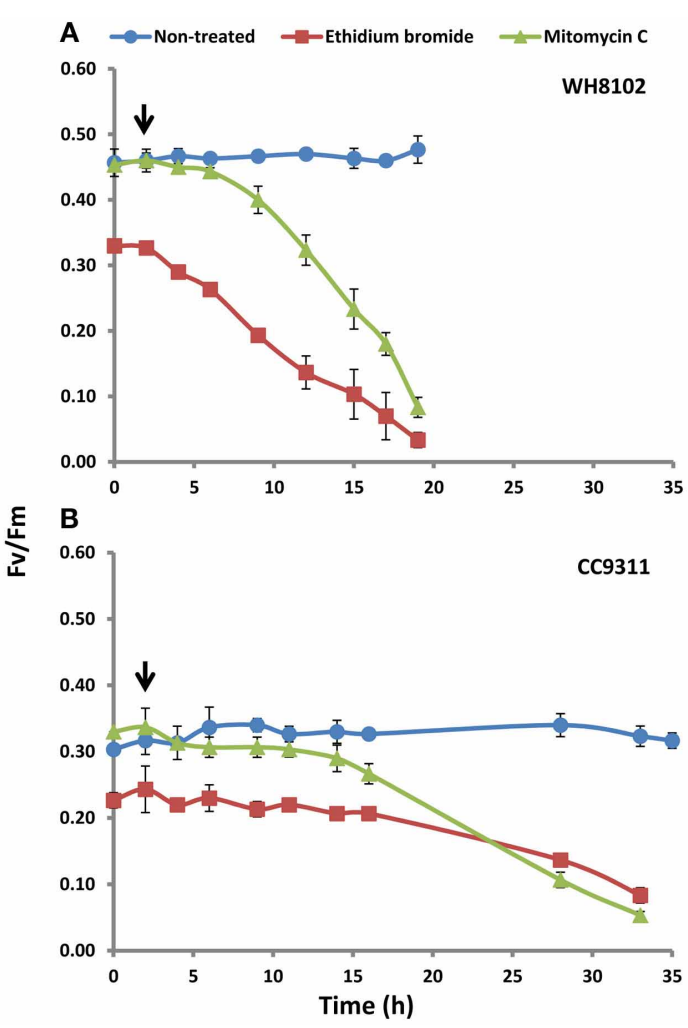

FIGURE A2 | Photosynthetic efficiency of photosystem II in (A) WH8102 and (B) CC9311 on treatment with EB and MC, and with no treatment as determined using PAM fluorometry. The axes represent $\mathrm{Fv} / \mathrm{Fm}$ (ratio of variable fluorescence and maximum fluorescence) against treatment time in hours. The experiment was carried out in triplicate and the mean plotted. The error bars represent standard deviation. The arrow represents the point of $2 \mathrm{~h}$ exposure at which RNA was isolated for microarray analysis. 
Table A1 | List of Synechococcus sp. CC9311 (A) and WH8102 (B) orthologous genes which showed strong (more than 2-fold) up- or downregulation in both strains in EB or MC treatments.

\begin{tabular}{|c|c|c|c|}
\hline A & & & \\
\hline sync_1804 possible beta-carotene ketolase & 2.63 & SYNW1368 & 1.39 \\
\hline sync_1816 predicted membrane protein & 2.07 & SYNW1452 & 1.29 \\
\hline sync_1805 conserved hypothetical protein & 1.69 & SYNW1369 & 1.06 \\
\hline sync_0622 possible cystathionine gamma-synthase & 1.43 & SYNW0674 & 1.69 \\
\hline sync_0950 AbrB family transcriptional regulator & 1.22 & SYNW1518 & 1.35 \\
\hline sync_2354 radical SAM enzyme, Cfr family & 1.13 & SYNW0617 & 1.12 \\
\hline sync_0355 cell division protein FtsH2 & 1.44 & SYNW0305 & -1.30 \\
\hline sync_2155 Photosystem I reaction center subunit III & -1.56 & SYNW1835 & -2.15 \\
\hline sync_1973 light-independent protochlorophyllide reductase, $\mathrm{N}$ subunit & -1.55 & SYNW1723 & -1.15 \\
\hline sync_2802 conserved hypothetical & -1.50 & SYNW2385 & -1.72 \\
\hline sync_2484 Ferredoxin thioredoxin reductase, catalytic beta chain & -1.35 & SYNW0318 & -1.62 \\
\hline sync_0014 RNA-binding region RNP-1 (RNA recognition motif) & -1.08 & SYNW0014 & -1.09 \\
\hline sync_2113 NADH-ubiquinone/plastoquinone oxidoreductase, B subunit & -1.01 & SYNW1873 & -1.71 \\
\hline sync_1409 Photosystem I reaction center subunit psaK & -2.73 & SYNW1290 & 1.24 \\
\hline sync_1581 GUN4-like family protein & -1.51 & SYNW1067 & 1.27 \\
\hline
\end{tabular}

\begin{tabular}{|c|c|c|c|}
\hline & MC treatment & & \\
\hline sync_0831 LexA repressor & 2.51 & SYNW1582 & 1.96 \\
\hline sync_1607 Nucleotidyltransferase/DNA polymerase & 2.25 & SYNW1043 & 1.39 \\
\hline sync_0443 recA protein & 1.48 & SYNW2062 & 3.08 \\
\hline sync_1545 ABC-type Fe3+ transport system periplasmic component & 1.05 & SYNW1797 & -1.66 \\
\hline sync_2323 allophycocyanin, alpha subunit & -2.44 & SYNW0485 & -1.36 \\
\hline sync_0488 phycocyanin, alpha subunit & -2.24 & SYNW2023 & -1.18 \\
\hline sync_0216 Heme oxygenase & -2.23 & SYNW0171 & -1.89 \\
\hline sync_1569 glutamine synthetase, type I & -2.18 & SYNW1073 & -1.89 \\
\hline sync_2092 hypothetical-related protein & -2.06 & SYNW1893 & -2.64 \\
\hline sync_0489 phycocyanin, beta subunit & -1.76 & SYNW2022 & -2.06 \\
\hline sync_2907 Type II alt RNA polymerase sigma factor, sigma-70 family & -1.72 & SYNW2496 & -1.19 \\
\hline sync_0393 photosystem I core protein PsaA & -1.70 & SYNW2124 & -1.45 \\
\hline sync_0504 C-phycoerythrin class II alpha chain & -1.67 & SYNW2009 & -1.81 \\
\hline sync_0914 Predicted protein & -1.66 & SYNW0691 & -1.25 \\
\hline sync_0132 acyl carrier protein & -1.62 & SYNW0143 & -1.31 \\
\hline sync_0620 cysteine synthase A & -1.56 & SYNW0673 & -1.12 \\
\hline sync_1137 Photosystem II protein Y-related protein & -1.56 & SYNW0898 & -1.31 \\
\hline sync_2155 Photosystem I reaction center subunit III & -1.52 & SYNW1835 & -1.34 \\
\hline sync_0495 C-phycoerythrin class I beta chain & -1.39 & SYNW2008 & -2.33 \\
\hline
\end{tabular}


Table A1 | Continued

\begin{tabular}{|c|c|c|c|}
\hline \multicolumn{4}{|l|}{ A } \\
\hline \multirow[t]{2}{*}{ CC9311 gene with predicted function } & $\log _{2}$ fold change & WH8102 ortholog & $\log _{2}$ fold change \\
\hline & \multicolumn{3}{|l|}{ EB treatment } \\
\hline sync_0511 possible phycobilisome linker polypeptide & -1.38 & SYNW2001 & -1.44 \\
\hline sync_0562 Photosystem I reaction center subunit IV & -1.37 & SYNW1960 & -1.23 \\
\hline sync_0398 photosystem I reaction center subunit XI & -1.37 & SYNW2118 & -1.21 \\
\hline sync_0399 photosystem I subunit VIII-related protein & -1.36 & SYNW2117 & -1.56 \\
\hline sync_0502 Phycoerythrin class II gamma chain, linker polypeptide (L-R 32.1) & -1.31 & SYNW2010 & -1.88 \\
\hline sync_2871 high-affinity branched-chain amino acid transport protein livH & -1.27 & SYNW2441 & -1.76 \\
\hline sync_2154 photosystem I reaction center subunit IX-related protein & -1.26 & SYNW1836 & -1.20 \\
\hline sync_0516 Possible phycobilisome linker polypeptide & -1.26 & SYNW1989 & -2.26 \\
\hline sync_2936 Sucrose phosphate synthase & -1.22 & SYNW2520 & -1.63 \\
\hline sync_1967 ribulose bisphosphate carboxylase, large subunit & -1.08 & SYNW1718 & -1.23 \\
\hline sync_0080 possible photosystem II protein PsbZ & -1.06 & SYNW0081 & -1.20 \\
\hline sync_0487 Protein of unknown function (DUF1001) superfamily & -1.71 & SYNW2003 & 1.01 \\
\hline sync_2330 conserved hypothetical protein & -1.54 & SYNW1951 & 2.06 \\
\hline
\end{tabular}

WH8102 gene with predicted function

$\log _{2}$ fold change

CC9311 ortholog

$\log _{2}$ fold change

\section{EB treatment}

SYNW1906 conserved hypothetical protein

SYNW0674 possible cystathionine gamma-synthase

SYNW1555 hypothetical

SYNW1368 possible beta-carotene ketolase

SYNW1518 conserved hypothetical protein

SYNW1452 predicted membrane protein (COG2259)

SYNW0617 conserved hypothetical protein

SYNW1369 conserved hypothetical protein

SYNW1067 conserved hypothetical protein

SYNW1290 possible photosystem I reaction center subunit $X$

SYNW1835 Photosystem I reaction center subunit III (PsaF)

SYNW2385 conserved hypothetical

SYNW1873 NADH dehydrogenase I chain 2 (or N)

SYNW1073 Glutamine synthetase, glutamate-ammonia ligase

SYNW0318 Ferredoxin thioredoxin reductase, beta chain

SYNW1893 hypothetical

SYNW1723 light-independent protochlorophyllide reductase

SYNW0014 RNA-binding region RNP-1

SYNW1529 cytochrome c oxidase subunit I

SYNW1725 Protochlorophyllide reductase iron-sulfur ATP-binding protein

SYNW0305 cell division protein $\mathrm{FtsH} 2$

1.78
1.69
1.67
1.39
1.35
1.29
1.12
1.06
1.27
1.24
-2.15
-1.72
-1.71
-1.70
-1.62
-1.32
-1.15
-1.09
-1.04
-1.03
-1.30

sync_0955

sync_0622

sync_1654

sync_1804

sync_0950

sync_1816

sync_2354

sync_1805

sync_1581

sync_1409

sync_2155

sync_2802

sync_2113

sync_1569

sync_2484

sync_2092

sync_1973

sync_0014

sync_1928

sync_1975

sync_0355

$\begin{array}{r}1.78 \\ 1.43 \\ 1.84 \\ 2.63 \\ 1.22 \\ 2.07 \\ 1.13 \\ 1.69 \\ -1.51 \\ -2.73 \\ -1.56 \\ -1.50 \\ -1.01 \\ -1.76 \\ -1.35 \\ -2.43 \\ -1.55 \\ -1.08 \\ -1.70 \\ -3.03 \\ 1.44 \\ \hline\end{array}$

\section{MC treatment}

SYNW2062 RecA bacterial DNA recombination protein

SYNW1405 conserved hypothetical protein

SYNW1043 putative UmuC protein

SYNW1582 SOS function regulatory protein, LexA repressor

SYNW2003 CpeT homolog

\begin{tabular}{llc}
3.08 & sync_0443 & 1.48 \\
2.49 & sync_1474 & 2.16 \\
1.39 & sync_1607 & 2.25 \\
1.96 & sync_0831 & 2.51 \\
1.01 & sync_0487 & -1.71 \\
\hline & & (Continued)
\end{tabular}


Table A1 | Continued

\begin{tabular}{|c|c|c|c|}
\hline \multicolumn{4}{|l|}{ A } \\
\hline \multirow[t]{2}{*}{ CC9311 gene with predicted function } & $\log _{2}$ fold change & WH8102 ortholog & $\log _{2}$ fold change \\
\hline & \multicolumn{3}{|l|}{ EB treatment } \\
\hline SYNW1951 conserved hypothetical & 2.06 & sync_2330 & -1.54 \\
\hline SYNW2008 C-phycoerythrin class II beta chain & -2.33 & sync_0495 & -1.39 \\
\hline SYNW1989 Possible phycobilisome linker polypeptide & -2.26 & sync_0516 & -1.26 \\
\hline SYNW2010 C-phycoerythrin class II gamma chain, linker & -1.88 & sync_0502 & -1.31 \\
\hline SYNW2441 putative urea ABC transporter & -1.76 & sync_2871 & -1.27 \\
\hline SYNW2520 putative sucrose phosphate synthase & -1.63 & sync_2936 & -1.22 \\
\hline SYNW2117 photosystem I subunit VIII (Psal) & -1.56 & sync_0399 & -1.36 \\
\hline SYNW1723 light-independent protochlorophyllide reductase & -1.46 & sync_1973 & -1.17 \\
\hline SYNW2001 possible phycobilisome linker polypeptide & -1.44 & sync_0511 & -1.38 \\
\hline SYNW0898 possible photosystem II PsbY protein & -1.31 & sync_1137 & -1.56 \\
\hline SYNW1718 Ribulose bisphosphate carboxylase, large chain & -1.23 & sync_1967 & -1.08 \\
\hline SYNW1960 photosystem I subunit IV (PsaE) & -1.23 & sync_0562 & -1.37 \\
\hline SYNW2118 putative photosystem I reaction center subunit XI & -1.21 & sync_0398 & -1.37 \\
\hline SYNW0081 possible photosystem II protein PsbZ (ycf9) & -1.20 & sync_0080 & -1.06 \\
\hline SYNW1836 photosystem I reaction center subunit IX (PsaJ) & -1.20 & sync_2154 & -1.26 \\
\hline SYNW0820 Protoporphyrin IX Magnesium chelatase subunit & -1.16 & sync_1220 & -1.18 \\
\hline SYNW0673 O-acetylserine (thiol)-lyase A & -1.12 & sync_0620 & -1.56 \\
\hline SYNW1797 putative iron $A B C$ transporter, substrate binding protein & -1.66 & sync_1545 & 1.05 \\
\hline
\end{tabular}

Genes which responded significantly, but in the opposite direction, are highlighted in gray. 